\title{
Merv Fingas (Ed): In-Situ Burning for Oil Spill Countermeasures
}

\author{
Edward R. Adlard ${ }^{1}$
}

c) Springer-Verlag GmbH Germany, part of Springer Nature 2018

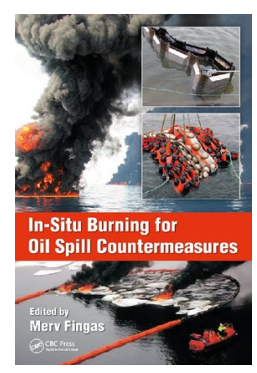

Bibliography

In-Situ Burning for Oil Spill Countermeasures Merv Fingas (Ed)

CRC Press, Boca Raton, FL, USA, pp xi+463

ISBN 978-1-138-73525-5

GBP 115.00, USD 149.95

It is a sad fact that wherever crude oil is produced, processed, or transported, some of it will leak into the environment. In the 51 years, since the Torrey Canyon was wrecked off the coast of Cornwall scarcely, a month has passed without an accident somewhere in the world ranging from a spill of few tons (of no consequence in the open ocean but potentially serious in inland waters) to the discharge of many thousand tons as in the worst case scenario of the Deepwater Horizon blowout in April 2011. Reference to the Torrey Canyon is appropriate here, since it was almost the first attempt to get rid of the spilt oil by burning it, although it was unsuccessful (see page 8 ). This attempt was accompanied by the use of detergents which proved to be as toxic to marine life as the oil itself. The use of modern dispersants (detergents) as one of the alternatives to oil removal is discussed on page 20 .
The book points out that in-situ burning is just one method of dealing with an oil spill as is the use of dispersants. In fact, every spill is unique in some respect or other and how it is tackled depends on such factors as the amount and type of oil, weather conditions, and sea temperature. Very occasionally, it may be unnecessary to do anything — in 1993, the MV Braer spilts 85,000 tons of oil, but (a) it was very light oil and (b) there was a force 10 gale blowing at the time. After $48 \mathrm{~h}$, the only signs of the spill were a large number of dead birds and seals with respiratory problems.

The title of the book is a concise and accurate description of its subject matter and content. Dr Fingas is listed as the editor and it is true in that there are four other authors, but Fingas is by far the largest contributor and one wonders why he bothered to include the other material. The introductory chapter by him is over a third of the book and represents a masterclass on the topic. The chapters by the other authors concern specific topics such burning on land (Chapter 2) and burning operations during the Deepwater Horizon blowout (Chapter 4).

Unfortunately, as pointed out above, sooner or later, those responsible for producing, transporting, or refining crude oil to be faced with the task of dealing with the consequences of a spill. This book provides an invaluable guide as to how to deal with such a situation.
Edward R. Adlard

e.adlard77@btinternet.com

1 Burton, UK 